\title{
Changes in Transporters and Metabolizing Enzymes in the Livers of Rats with Bile Duct Ligation
}

\author{
Atsushi Kawase ${ }^{1}$, Akira Kazaoka ${ }^{1}$, Rei Yamamoto ${ }^{1}$, Risa Minakata ${ }^{1}$, Hiroaki Shimada ${ }^{1}$, Masahiro Iwaki ${ }^{1,2,3}$ \\ 1. Department of Pharmacy, Faculty of Pharmacy, Kindai University, Osaka, Japan. 2. Pharmaceutical Research and \\ Technology Institute, Kindai University, Osaka, Japan. ${ }^{3}$. Antiaging Center, Kindai University, Osaka, Japan.
}

Received, July 11, 2019; Revised, September 8, 2019; Accepted, September 9, 2019; Published, September 16, 2019.

\begin{abstract}
Purpose: Bile duct ligation (BDL) in experimental animals is widely used as an animal model of liver cholestasis and fibrosis. The transcriptional process and plasma membrane localization of transporters are regulated by nuclear receptors and scaffold proteins, respectively. However, the detailed changes of these factors in the livers of BDL rats remain unclear. To clarify the effects of BDL on the levels of transporters and metabolizing enzymes, nuclear receptors, and scaffold proteins, we investigated changes in mRNA and protein levels of livers from BDL rats. Methods: Membrane proteins and microsomes were prepared from rats with BDL. The mRNA levels of transporters and nuclear receptors in livers of control and BDL rats were examined by real-time reverse transcription polymerase chain reaction. The protein levels of transporters, metabolizing enzymes and scaffold proteins in membrane proteins and microsomes were determined by liquid chromatography-tandem mass spectrometry-based targeted proteomics. Results: Mdr1a mRNA was significantly decreased at 1 and 2 weeks of BDL. The mRNA levels of MRP2 were significantly decreased. The mRNA levels of nuclear receptors were significantly decreased in livers of 1-week BDL rats. The protein levels of P-gp were significantly increased by BDL. Regarding scaffold proteins, the protein levels of ezrin, moesin and EBP50 were significantly decreased at 2 weeks of BDL. The protein levels of radixin were significantly increased at 1 week of BDL. In 1-week BDL rats, the protein levels of metabolizing enzymes such as CYP and UGT were significantly decreased. Conclusions: This study reports the comprehensive changes of transporters, metabolizing enzymes, nuclear receptors, and ezrin/radixin/moesin proteins in the livers of BDL rats. The expression levels of nuclear receptors and radixin that regulate the transcription and localization of CYP and/or transporters were decreased by BDL.
\end{abstract}

\section{INTRODUCTION}

The inhibition of the biliary excretion of bile acid leads to an increased accumulation of bile acid in hepatocytes. Occasionally, the intracellular accumulation of bile acid triggers cholestasis and fibrogenesis following liver injury $(1,2)$. Bile duct ligation (BDL) in experimental animals is widely used as an animal model of liver cholestasis and fibrosis (3-5). BDL rats exhibit a high level of cirrhosis with morphological changes similar to human biliary cirrhosis (4).

The hepatic concentrations of drugs and drug metabolites are regulated by the interplay between transporters and metabolizing enzymes in hepatocytes. For example, drug metabolites formed by metabolizing enzymes such as cytochrome P450 (CYP) and UDP-glucuronosyltransferase (UGT) underwent biliary excretion via efflux transporters such as P-glycoprotein (P-gp/ABCB1), multidrug resistance-associated protein 2 (MRP2/ABCC2) and breast cancer resistance protein (BCRP/ABCG2) on a canalicular membrane. Metabolizing enzymes and transporters are transcriptionally regulated by nuclear receptors such as pregnane $\mathrm{X}$ receptor (PXR, NR1I2), constitutive androstane receptor (CAR, NR1I3), retinoid $X$ receptor (RXR) and cytoplasmic CAR retention protein (CCRP) (6-8). The plasma membrane localization of efflux transporters on the canalicular membrane is important for this transport activity. Ezrin/radixin/moesin (ERM) proteins participate as a scaffold protein in the plasma membrane localization of efflux transporters (9-11). Previous report shows that radixin knockout mice loses the localization of MRP2 on the canalicular membrane (12).

The hepatic expression of some metabolizing enzymes in BDL rats is decreased $(13,14)$. The expression of efflux transporters on the canalicular membrane might have been elevated because of an adaptation to the liver injury (15-17).

Corresponding Author: Atsushi Kawase, Ph.D., Department of Pharmacy, Faculty of Pharmacy, Kindai University, 3-4-1 Kowakae, Higashi-Osaka, Osaka 577-8501, Japan; E-mail: kawase@phar.kindai.ac.jp 
However, a comprehensive understanding of the changes in transporters, metabolizing enzymes, nuclear receptors, and ERM proteins in the livers of BDL rats is poorly understood, although these changes might affect drug disposition, efficiency and adverse reaction of various drugs. This background prompted us to clarify the effects of BDL on changes in metabolizing enzymes and transporters in the liver.

\section{METHODS}

\section{Animals and treatment}

The study protocol was approved by the Committee for the Care and Use of Laboratory Animals of the School of Pharmacy of Kindai University (Osaka, Japan). Male Wistar/ST rats (7-weeks-old, body weight 200-220 g) were purchased from Japan SLC (Shizuoka, Japan). The animals were housed in an air-conditioned room at $22 \pm 0.5^{\circ} \mathrm{C}$ and relative air humidity of $55 \pm 10 \%$ with a 12 -h lighting schedule (7:00 AM-7:00 PM) and were given free access to standard laboratory food (MF, Oriental Yeast Co., Tokyo, Japan) and water on the light/dark schedule for 1 week before they were divided into groups. Rats were anesthetized with pentobarbital $(50 \mathrm{mg} / \mathrm{kg}$, i.p., this treatment did not affect the CYP expression in 1,2, and 3 weeks control and BDL rats). The bile duct was exposed and double ligated with 5-0 silk after making an approximately $2-\mathrm{cm}$ incision in the abdomen with a microdissecting scissor. The bile duct of sham-operated animals was exposed but not ligated and these were used as control rats. After suturing the skin, rats were maintained under the above conditions. The livers of rats anesthetized with isoflurane were perfused with ice-cold physiologic $(0.9 \%)$ saline and removed at 1,2 or 3 weeks after ligation of the bile duct. After flash freezing in liquid nitrogen, each sample was preserved at $-80^{\circ} \mathrm{C}$ until used for RNA extraction, and microsome and membrane protein preparation.

\section{Chemicals and reagents}

Sepasol RNA I Super G was from Nacalai Tesque (Kyoto, Japan). ReverTra Ace was from Toyobo Life Science (Osaka, Japan). Fast SYBR Green Master Mix, Mem-PER eukaryotic membrane protein extraction reagent kit, and $\mathrm{BCA}$ protein assay kit were from Thermo Fisher Scientific (Waltham, MA, USA). Oligonucleotide primers were purchased from Sigma-Aldrich (St. Louis, MO, USA). Mass spectrometry (MS) grade porcine pancreatic trypsin and OASIS HLB were obtained from Wako Pure Chemicals (Osaka, Japan) and Waters (Milford, MA, USA), respectively. All other chemicals and solvents were of MS grade or the highest commercially available purity.

Determination of mRNA levels by real-time reverse transcription polymerase chain reaction (RT-PCR)

Total RNA was extracted from livers of control and BDL rats using Sepasol RNA I Super G. The mRNA expression levels were measured by RT-PCR as described previously (18). The oligonucleotide sequences for each mRNA target are shown in Table 1. Data were analyzed using StepOne Software (Thermo Fisher Scientific) using the multiplex comparative method.

\section{Preparation of membrane proteins and liver microsomes}

Membrane proteins were extracted from livers using a Mem-PER eukaryotic membrane protein extraction reagent kit.

Table 1. Primer sequences used in PCR assays

\begin{tabular}{cll}
\hline Gene & \multicolumn{1}{c}{ Forward $\left(5^{\prime}-3^{\prime}\right)$} & \multicolumn{1}{c}{ Reverse $\left(5^{\prime}-3^{\prime}\right)$} \\
\hline$M d r 1 a$ & GTGAAAGGGGCTACAGGGTC & AGTGTCAATTGCCAGCCGTA \\
$M d r 1 b$ & GGCCTTAACGGAACAGCAGA & CTGCATAGCGAAACATCCCG \\
$M R P 2$ & CTCGGTCTTATGCGGCGTATT & TCTGGAAACCGTAGGAGACGAA \\
$M R P 3$ & TGAAGTTCAAAGACTCCCGCA & TCTACCTGCTCCAAGAAGGTGG \\
$B C R P$ & TGTGTAGGTCGGTGTGCGAG & ATCTATGCCTTTCTAGCTGTCCC \\
$B S E P$ & AAGCTGGCAAAGGGTTGTTG & AGCCAACTCGAATGTCTCCC \\
$O C T 1$ & CCAATAGCGGCCTCGAATCT & TGCAGCTCATGCGGGATAAA \\
$O C T N 1$ & AAGCCGCAAAGATGAATGGC & TTGTGGCAATGTTCCGAGTC \\
$O C T N 2$ & ACTACGTGGCAGCATTTGTC & TATGCAAACAGAGGCAGCAC \\
$P X R$ & GACGGCAGCATCTGGAACTAC & TGATGACGCCCTTGAACATG \\
$C A R$ & CCACGGGCTATCATTTCCAT & CCCAGCAAACGGACAGATG \\
$R X R$ & CCGCTCCATAGCTGTGAAAGA & TCCGTTAGCACCCTGTCAAAG \\
$C C R P$ & TGCAATGGCAGCATGTCGTA & ATACTCCATGACCGCATTGGC \\
$G A P D H$ & CAACGACCCCTTCATTGA & CAGTGATGGCATGGACTG \\
\hline
\end{tabular}


Liver microsomes from control and BDL rats were prepared according to previously described methods (19). The protein concentrations of membrane proteins and liver microsomes were measured using a BCA protein assay kit.

\section{Measuring protein levels of transporters, metabolizing enzymes and scaffold proteins by targeted proteomics}

The protein expression of liver microsomes and plasma membrane proteins of the liver were determined by liquid chromatography-tandem mass spectrometry-based targeted proteomics, as described previously $(20,21)$. Liver microsomes were used to determine metabolizing enzyme expressions and plasma membrane proteins were used to determine transporter and scaffold protein levels.

\section{STATISTICAL ANALYSIS}

Data are shown as the mean \pm standard error of the mean $(n=3-5)$. Relationships between the mRNA levels of nuclear receptors and transporters were evaluated by Pearson's correlation and regression analysis using GraphPad Prism software version 5 (GraphPad Software, Inc., La Jolla, CA, USA). Significance of differences between mean values was determined by Dunnett's test after analysis of variance using GraphPad Prism software. Values of $p<0.05$ were considered to indicate statistical significance.

\section{RESULTS}

The effects of BDL on the mRNA levels of transporters and nuclear receptors in livers are shown in Figures 1 and 2. mRNA levels of transporters such as Mdr1a, Mdr1b, MRP2, MRP3, BCRP, bile salt export pump (BSEP), organic cation transporter (OCT)1, carnitine/organic cation transporter (OCTN)1 and OCTN2 in livers from control and BDL rats relative to controls are shown in Figure 1. The mRNA levels of Mdrla were significantly increased and whereas mRNA levels of Mdrlb were reduced in BDL rats. Mdrla mRNA was significantly decreased at 1 and 2 weeks of BDL and Mdr $1 \mathrm{~b}$ mRNA was significantly increased at 1 week of BDL. Regarding the other efflux transporters on the canalicular membrane, the mRNA levels of MRP2 were significantly decreased and the mRNA levels of BCRP tended to decrease similar to Mdrla mRNA. The mRNA levels of the other examined transporters in BDL rats also tended to decrease compared with control rats. Relative mRNA levels for PXR, CAR, RXR and CCRP in livers from control and BDL rats are shown in Figure 2. The mRNA levels of PXR, CAR, RXR and CCRP were significantly decreased in livers of 1 -week BDL rats compared with control rats. The decreased mRNA levels of CAR and RXR were maintained up to 3 weeks.

Expression levels did not necessarily exhibit corresponding changes between mRNA and protein levels. The protein levels for transporters, scaffold proteins and metabolizing enzymes in the livers of control and BDL rats are shown in Figures 3 and 4. Protein levels for P-gp, MRP2, BCRP, OAT2, ezrin, radixin, moesin and ezrin-radixin-moesin-binding phosphoprotein of $50 \mathrm{kDa}$ (EBP50) in membrane proteins of livers from control and $\mathrm{BDL}$ rats relative to controls are shown in Figure 3. The protein levels of P-gp were significantly increased by BDL at 1,2 and 3 weeks. The other efflux transporters such as MRP2 and BCRP on the canalicular membrane were significantly increased at 1 week but not 2 and 3 weeks of BDL. Protein levels of OAT2 tended to be decreased. The protein levels of the scaffold proteins ezrin, moesin and EBP50 were significantly decreased at 2 weeks of BDL. Ezrin and EBP50 were significantly decreased at 3 weeks of BDL. The protein levels of radixin were significantly increased at 1 week but not 2 and 3 weeks of BDL. Relative protein levels of CYP1A1, CYP1A2, CYP1B1, CYP2A1, CYP2C6, CYP2C11, CYP2D1, CYP2D3, CYP2E1, CYP3A1, CYP3A2, CYP3A9, UGT1A1, UGT1A3 and UGT2B1 in microsomes of livers from control and BDL rats are shown in Figure 4. In 1-week BDL rats, the protein levels of CYP1A1, CYP1B1, CYP2A1, CYP2C6, CYP2C11, CYP2D1, CYP2D3, CYP2E1, CYP3A1, CYP3A9, UGT1A1 and UGT2B1 were significantly decreased. In 2week BDL rats, the protein levels of CYP1A1, CYP2A1, CYP2D1, CYP3A1 were significantly decreased. In 3-week BDL rats, the protein levels of CYP1A1, CYP2C11, CYP2D3, CYP3A1 and UGT2B1 were significantly decreased.

\section{DISCUSSION}

The profiling of metabolizing enzymes and transporters in livers of 1-, 2- and 3-week BDL rats, an animal model of liver cholestasis and fibrosis, were examined. Regarding mRNA expressions, correlations of transporters with nuclear receptors were evaluated. To determine changes in the protein levels of efflux transporters, the protein levels of scaffold proteins were measured. 

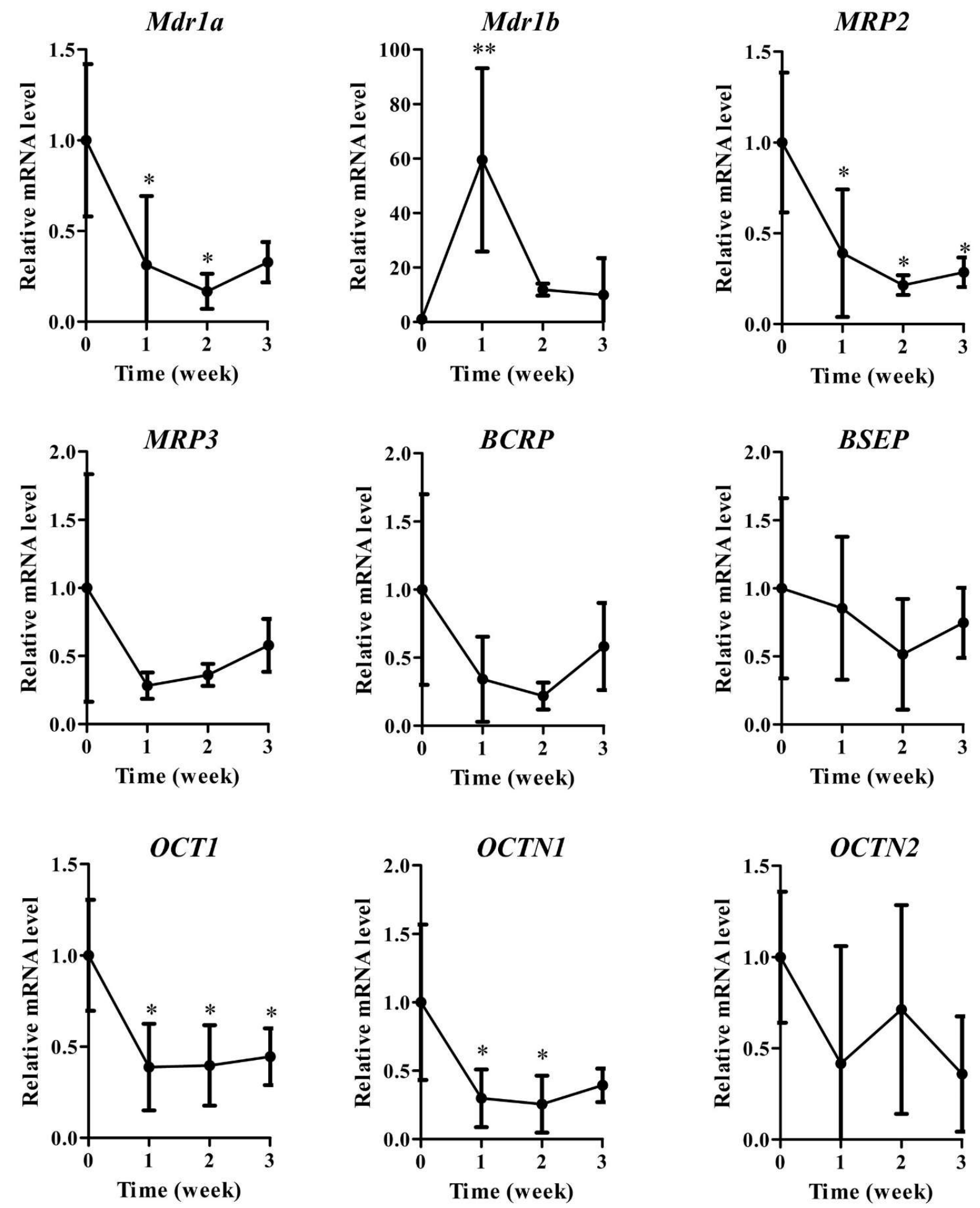

Figure 1. mRNA levels of Mdrla, Mdr1b, MRP2, MRP3, BCRP, BSEP, OCT1, OCTN1 and OCTN2 in livers from control and BDL rats relative to controls. Mdrla and $M d r 1 b$ are mRNA for P-gp. Significant differences $(* p<0.05$ and $* * p<0.01)$ vs controls. 

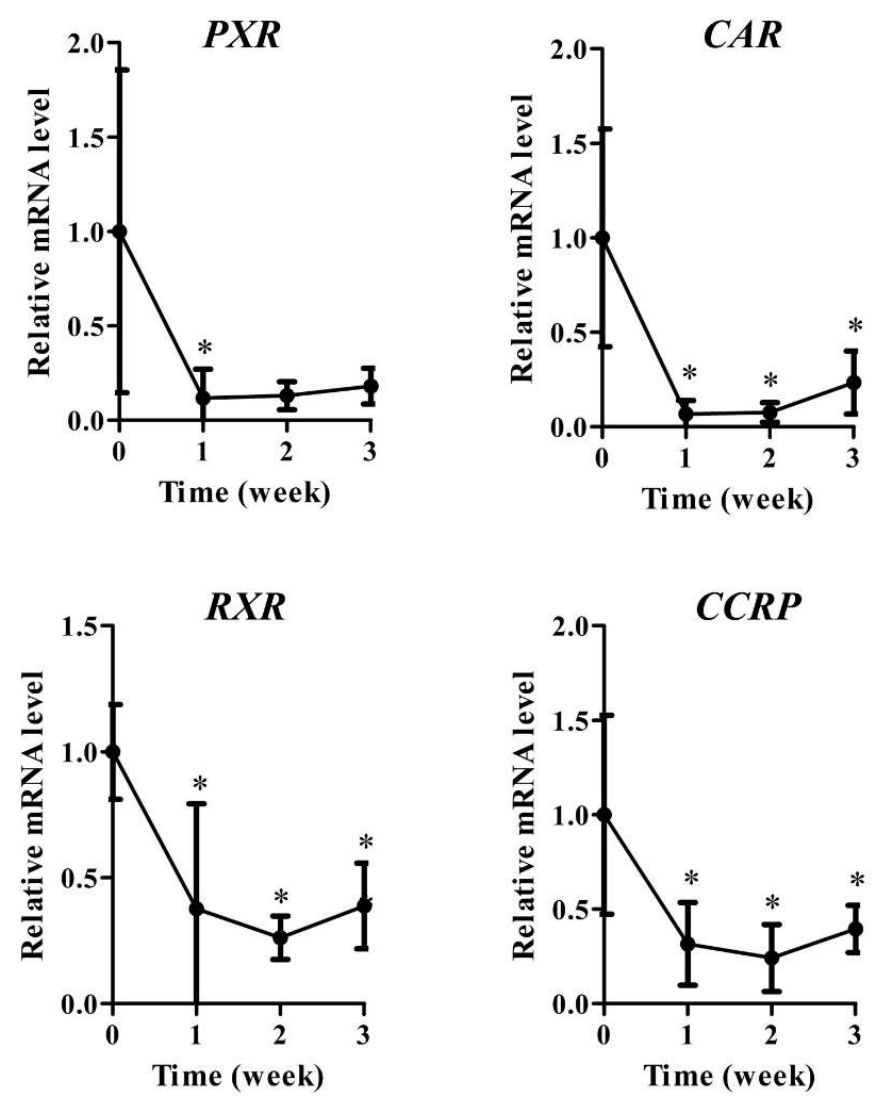

Figure 2. mRNA levels of $P X R, C A R, R X R$ and $C C R P$ in livers from control and BDL rats relative to controls. Significant differences $(* p<0.05)$ vs controls.
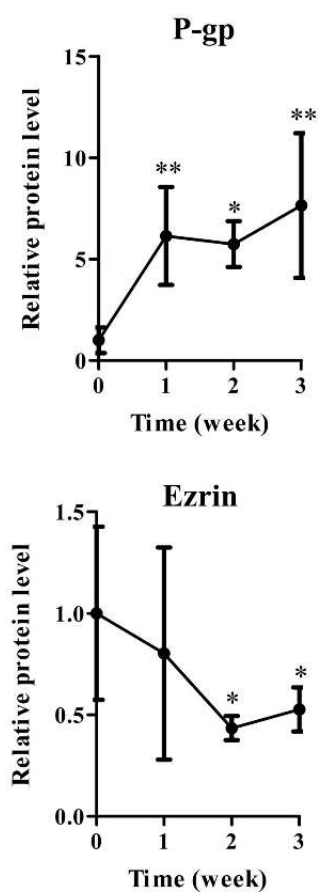



OAT2
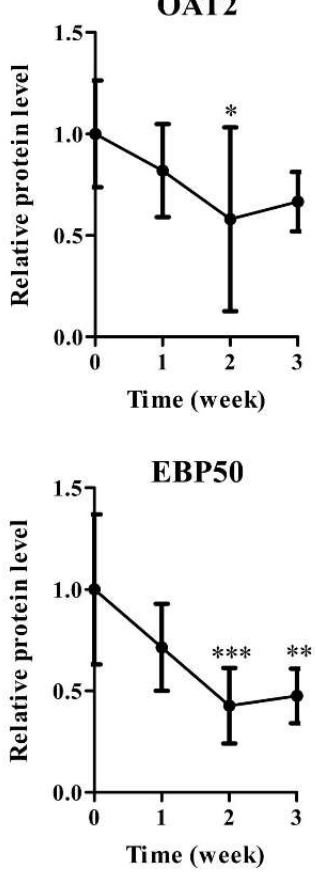

Figure 3. Protein levels of P-gp, MRP2, BCRP, OAT2, ezrin, radixin, moesin and EBP50 in membrane proteins of livers from control and BDL rats relative to controls. Significant differences $(* p<0.05, * * p<0.01$, and $* * * p<0.001)$ vs controls. 

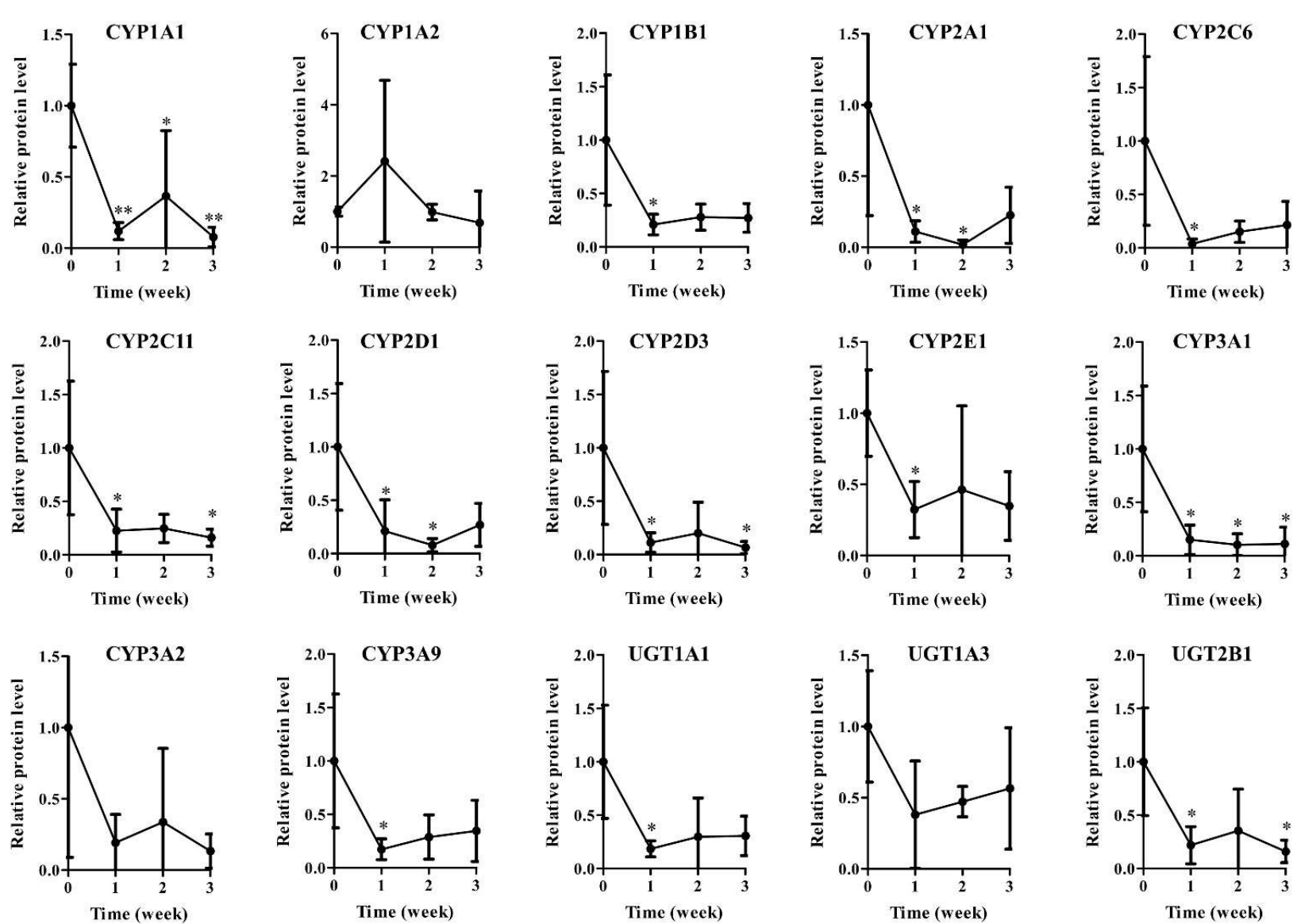

Figure 4. Protein levels of CYP1A1, CYP1A2, CYP1B1, CYP2A1, CYP2C6, CYP2C11, CYP2D1, CYP2D3, CYP2E1, CYP3A1, CYP3A2, CYP3A9, UGT1A1, UGT1A3 and UGT2B1 in microsomes of livers from control and BDL rats relative to controls. Significant differences $(* p<0.05$ and $* * p<0.01)$ vs controls.

The mRNA levels of transporters except Mdrlb in the livers of BDL rats were significantly decreased or tended to decrease. These results are consistent with the results of previous reports $(22,23)$. The mRNA levels of Mdrla and Mdr1b changed in the opposite direction. Other report also shows that the hepatic mRNA levels of Mdrla and Mdr1b are oppositely altered by inflammation (24). The mRNA levels of nuclear receptors in BDL rats were examined, because the consideration should be given to the intracellular localization (cytoplasm or nucleus) and phosphorylation state of nuclear receptors in the determination of protein levels of nuclear receptors. The mRNA levels of nuclear receptors in BDL rats were decreased similar to transporter mRNAs. In particular, the mRNA levels of nuclear receptors in 1-week BDL rats were decreased. PXR and CAR, which binds as a heterodimer with RXR in the nucleus, regulate the transcriptional process of CYP and transporters. CCRP forms complexes with CAR and heat shock protein $70(25,26)$. The mRNA levels of Mdr1a, MRP2, MRP3, BCRP, OCT1, OCTN1 strongly correlated with the mRNA levels of nuclear receptors, suggesting that a reduction of transcriptional regulation by nuclear receptors might decrease transporter mRNAs in BDL rats. There was no correlation between BSEP and nuclear receptors. Therefore, the transcription of BSEP is probably regulated by other nuclear receptors such as farnesoid $\mathrm{X}$ receptor and small heterodimer partner (27,28).

Previous studies report that the mRNA and protein levels of uptake transporters such as organic anion transporting polypeptide and OCT1 are reduced by $\mathrm{BDL}(22,29,30)$. In contrast, efflux transporters such as MRP2 are increased by BDL (31), although the mRNA levels of MRP2 are decreased by an intraperitoneal injection of inflammatory cytokines such as interleukin-1 $\square$, interleukin-6 and tumor necrosis factor- $\square$ to mice (32). P-gp protein is also increased in the livers of BDL rats up to 3 weeks similar to previous reports (15-17). These results support the view that an increase in efflux transporters on the canalicular membrane reflect an adaptation to liver injury. The 
amount of bile acid in the liver is altered by BDL. For example, the concentration of bile acid in the livers of BDL rats was increased approximately 10fold and the concentrations of deoxycholic acid and hyodeoxycholic acid are decreased (33). However, the involvement of bile acid in the regulation of transporters is likely to be minor (32). To date, changes in hepatic efflux transporter expression in BDL rats are controversial (17,34-36). Further studies are needed to clarify the changes of MRP2 in $\mathrm{BDL}$ rats.

The localization of transporters such as MRP2 and P-gp on the canalicular membrane is regulated by scaffold proteins such as ERM proteins. Radixin has a linker activity for efflux transporters $(12,37)$. The protein levels of radixin in the membrane proteins of 1-week BDL rats corresponded to those of MRP2 (Figure 3). The protein levels of ezrin and EBP50 in 2- and 3-week BDL rats were significantly decreased compared with control rats. These results suggested that radixin is dominantly involved in the plasma membrane localization of efflux transporters compared with ezrin, moesin and EBP50. The changed expression of nuclear receptors and radixin in BDL rats might participate in the regulation of the expression of transporter proteins.

The protein levels of transporters did not exhibit corresponding changes with their mRNA levels, suggesting the post-transcriptional process and/or plasma membrane localization of transporters as well as the transcriptional process might be modulated by BDL. Therefore, changes in the mRNA levels of transporters in BDL rats might not reflect the activity of transporters.

The expressions of CYP in liver microsomes and of transporters is transcriptionally regulated by nuclear receptors (38-40). Previous reports demonstrate that the hepatic levels of CYP are reduced by BDL $(13,41)$. The current study also shows that the protein levels of the CAR target gene CYP2C and PXR target gene CYP3A in liver microsomes of BDL rats were significantly decreased (Figure 4). The decreased levels of nuclear receptors such as CAR and PXR in the liver microsomes of BDL rats might inhibit the transcriptional process of CYP isoforms. Drug pharmacokinetics are affected by decreased levels of CYP isoforms in BDL rats $(42,43)$. Thus, the elimination of other drugs from the body might be delayed by BDL. Further studies on the effects of BDL on altered drug pharmacokinetics are required. BDL rats show the states of liver injury or toxicity accompanying cholestasis and fibrosis (3-5). The decreases of CYP activities in these states might result in the reduction of metabolism of drugs and induction of adverse effects of drugs.

In conclusion, this study reports on the comprehensive changes of transporters, metabolizing enzymes, nuclear receptors, and ERM proteins in the livers of BDL rats. The decrease in nuclear receptors might participate in downregulating the expression of CYP in the liver microsomes of BDL rats. In addition to nuclear receptors, reduced radixin in BDL rats might inhibit the plasma membrane localization of transporters.

\section{CONFLICT OF INTEREST}

The authors declare no conflict of interest.

\section{ACKNOWLEDGEMENTS}

This work was supported by JSPS KAKENHI Grant Number 18K06806, the Japanese Ministry of Education, Culture, Sports, Science, and Technology (MEXT). We thank Edanz Group (www.edanzediting.com/ac) for editing a draft of this manuscript.

\section{REFERENCES}

1. Radominska A, Treat S, Little J. Bile acid metabolism and the pathophysiology of cholestasis. Semin Liver Dis. 1993;13(3):219-34. DOI: 10.1055/s-2007-1007351

2. Cai S-Y, Ouyang X, Chen Y, Soroka CJ, Wang J, Mennone A, et al. Bile acids initiate cholestatic liver injury by triggering a hepatocyte-specific inflammatory response. JCI Insight. 2017;2(5):e90780. DOI: 10.1172/jci.insight.90780

3. Ayvaz S, Kanter M, Aksu B, Sahin SH, Uzun H, Erboga M, et al. The effects of hyperbaric oxygen application against cholestatic oxidative stress and hepatic damage after bile duct ligation in rats. J Surg Res. 2013;183(1):146-55. DOI: 10.1016/j.jss.2012.12.036

4. Kountouras J, Billing BH, Scheuer PJ. Prolonged bile duct obstruction: a new experimental model for cirrhosis in the rat. Br J Exp Pathol. 1984;65(3):30511.

5. Tag CG, Sauer-Lehnen S, Weiskirchen S, BorkhamKamphorst E, Tolba RH, Tacke F, et al. Bile Duct Ligation in Mice: Induction of Inflammatory Liver Injury and Fibrosis by Obstructive Cholestasis. J Vis Exp. 2015;(96). DOI: 10.3791/52438

6. Kliewer SA, Moore JT, Wade L, Staudinger JL, Watson MA, Jones SA, et al. An orphan nuclear receptor activated by pregnanes defines a novel steroid signaling pathway. Cell. 1998;92(1):73-82. DOI: 10.1016/s0092-8674(00)80900-9

7. Honkakoski P, Zelko I, Sueyoshi T, Negishi M. The nuclear orphan receptor CAR-retinoid $\mathrm{X}$ receptor 
heterodimer activates the phenobarbital-responsive enhancer module of the CYP2B gene. Mol Cell Biol. 1998;18(10):5652-8. DOI: 10.1128/mcb.18.10.5652

8. Waxman DJ. P450 Gene Induction by Structurally Diverse Xenochemicals: Central Role of Nuclear Receptors CAR, PXR, and PPAR. Arch Biochem Biophys. 1999;369(1):11-23.

DOI: 10.1006/abbi.1999.1351

9. Suda J, Zhu L, Karvar S. Phosphorylation of radixin regulates cell polarity and Mrp-2 distribution in hepatocytes. Am J Physiol Cell Physiol. 2011;300(3):C416-24.

DOI: 10.1152/ajpcell.00467.2010

10. Yonemura S, Matsui T, Tsukita S, Tsukita S. Rhodependent and -independent activation mechanisms of ezrin/radixin/moesin proteins: an essential role for polyphosphoinositides in vivo. J Cell Sci. 2002;115(Pt 12):2569-80.

11. Wang W, Soroka CJ, Mennone A, Rahner C, Harry $\mathrm{K}$, Pypaert $\mathrm{M}$, et al. Radixin is required to maintain apical canalicular membrane structure and function in rat hepatocytes. Gastroenterology. 2006;131(3):878-84. DOI: 10.1053/j.gastro.2006.06.013

12. Kikuchi S, Hata M, Fukumoto K, Yamane Y, Matsui $\mathrm{T}$, Tamura A, et al. Radixin deficiency causes conjugated hyperbilirubinemia with loss of Mrp2 from bile canalicular membranes. Nat Genet. 2002;31(3):320-5. DOI: 10.1038/ng905

13. Chen J, Murray M, Liddle C, Jiang XM, Farrell GC. Downregulation of male-specific cytochrome P450s $2 \mathrm{C} 11$ and $3 \mathrm{~A} 2$ in bile duct-ligated male rats: importance to reduced hepatic content of cytochrome P450 in cholestasis. Hepatology. 1995;22(2):580-7.

14. Tateishi $T$, Watanabe $M$, Nakura $H$, Tanaka M, Kumai T, Kobayashi S. Liver damage induced by bile duct ligation affects CYP isoenzymes differently in rats. Pharmacol Toxicol. 1998;82(2):89-92. DOI: 10.1111/j.1600-0773.1998.tb01403.x

15. Accatino L, Pizarro M, Solís N, Koenig CS, Vollrath V, Chianale J. Modulation of hepatic content and biliary excretion of P-glycoproteins in hepatocellular and obstructive cholestasis in the rat. J Hepatol. 1996;25(3):349-61. DOI: 10.1016/s01688278(96)80122-x

16. Hyogo $H$, Tazuma $S$, Nishioka $T$, Ochi $H$, Yamaguchi A, Numata Y, et al. Phospholipid alterations in hepatocyte membranes and transporter protein changes in cholestatic rat model. Dig Dis Sci. 2001;46(10):2089-97.

DOI: 10.1023/a:1011934108920

17. Kagawa T, Watanabe N, Sato M, Nakano A, Nishizaki Y, Hosoi K, et al. Differential expression of multidrug resistance (mdr) and canalicular multispecific organic anion transporter (cMOAT) genes following extrahepatic biliary obstruction in rats. Biochem Mol Biol Int. 1998;44(3):443-52.

18. Kawase A, Fujii A, Negoro M, Akai R, Ishikubo M, Komura H, et al. Differences in cytochrome P450 and nuclear receptor mRNA levels in liver and small intestines between SD and DA rats. Drug Metab Pharmacokinet. 2008;23(3):196-206.

19. Uno S, Fujii A, Komura H, Kawase A, Iwaki M. Prediction of metabolic clearance of diclofenac in adjuvant-induced arthritis rats using a substrate depletion assay. Xenobiotica. 2008;38(5):482-95. DOI: $10.1080 / 00498250801935982$

20. Kawase A, Tateishi S, Kazaoka A. Profiling of hepatic metabolizing enzymes and nuclear receptors in rats with adjuvant arthritis by targeted proteomics. Biopharm Drug Dispos. 2018;39(6):308-14. DOI: 10.1002/bdd. 2147

21. Kawase A, Inoue Y, Nakazaki S, Koizumi E, Iwaki M. Radixin knockdown improves the accumulation and efficiency of methotrexate in tumor cells. Oncol Rep. 2019;42(1):283-90. DOI: 10.3892/or.2019.7162

22. Dumont M, Jacquemin E, D'Hont C, Descout C, Cresteil D, Haouzi D, et al. Expression of the liver $\mathrm{Na}+$-independent organic anion transporting polypeptide (oatp-1) in rats with bile duct ligation. J Hepatol. 1997;27(6):1051-6. DOI: 10.1016/s01688278(97)80149-3

23. Trauner M, Arrese M, Soroka CJ, Ananthanarayanan M, Koeppel TA, Schlosser SF, et al. The rat canalicular conjugate export pump (Mrp2) is downregulated in intrahepatic and obstructive cholestasis. Gastroenterology. 1997;113(1):255-64. DOI: 10.1016/s0016-5085(97)70103-3

24. Goralski KB, Hartmann G, Piquette-Miller M, Renton KW. Downregulation of mdrla expression in the brain and liver during CNS inflammation alters the in vivo disposition of digoxin. Br J Pharmacol. 2003;139(1):35-48. DOI: 10.1038/sj.bjp.0705227

25. Timsit YE, Negishi M. Coordinated regulation of nuclear receptor CAR by CCRP/DNAJC7, HSP70 and the ubiquitin-proteasome system. Massoumi R, editor. PLoS One. 2014;9(5):e96092. DOI: 10.1371/journal.pone.0096092

26. Kobayashi K, Sueyoshi T, Inoue K, Moore R, Negishi M. Cytoplasmic accumulation of the nuclear receptor CAR by a tetratricopeptide repeat protein in HepG2 cells. Mol Pharmacol. 2003;64(5):1069-75. DOI: $10.1124 / \mathrm{mol} .64 .5 .1069$

27. Lew J-L, Zhao A, Yu J, Huang L, de Pedro N, Peláez F, et al. The Farnesoid X Receptor Controls Gene Expression in a Ligand- and Promoter-selective Fashion. J Biol Chem. 2004;279(10):8856-61. DOI: 10.1074/jbc.M306422200

28. Plass J, Mol O, Heegsma J, Geuken M, Faber KN, Jansen PLM, et al. Farnesoid X receptor and bile salts are involved in transcriptional regulation of the gene encoding the human bile salt export pump. Hepatology. 2002;35(3):589-96. DOI: 10.1053/jhep.2002.31724

29. Denk GU, Soroka CJ, Mennone A, Koepsell H, Beuers U, Boyer JL. Down-regulation of the organic cation transporter 1 of rat liver in obstructive cholestasis. Hepatology. 2004;39(5):1382-9. DOI: 10.1002/hep. 20176 
30. Donner MG, Schumacher S, Warskulat U, Heinemann J, Häussinger D. Obstructive cholestasis induces TNF-alpha- and IL-1 -mediated periportal downregulation of Bsep and zonal regulation of Ntcp, Oatp1a4, and Oatp1b2. Am J Physiol Gastrointest Liver Physiol. 2007;293(6):G1134-46. DOI: 10.1152/ajpgi.00079.2007

31. Slitt AL, Allen K, Morrone J, Aleksunes LM, Chen C, Maher JM, et al. Regulation of transporter expression in mouse liver, kidney, and intestine during extrahepatic cholestasis. Biochim Biophys Acta - Biomembr. 2007;1768(3):637-47. DOI: 10.1016/j.bbamem.2006.10.008

32. Hartmann G, Cheung AKY, Piquette-Miller M. Inflammatory Cytokines, but Not Bile Acids, Regulate Expression of Murine Hepatic Anion Transporters in Endotoxemia. J Pharmacol Exp Ther. 2002;303(1):273-81. DOI: 10.1124/jpet.102.039404

33. Kinugasa T, Uchida K, Kadowaki M, Takase H, Nomura Y, Saito Y. Effect of bile duct ligation on bile acid metabolism in rats. $J$ Lipid Res. 1981;22(2):201-7.

34. Lee J, Azzaroli F, Wang L, Soroka CJ, Gigliozzi A, Setchell KD, et al. Adaptive regulation of bile salt transporters in kidney and liver in obstructive cholestasis in the rat. Gastroenterology. 2001;121(6):1473-84. 10.1053/gast.2001.29608

35. Paulusma CC, Kothe MJ, Bakker CT, Bosma PJ, van Bokhoven I, van Marle J, et al. Zonal downregulation and redistribution of the multidrug resistance protein 2 during bile duct ligation in rat liver. Hepatology. 2000;31(3):684-93. DOI: 10.1002/hep.510310319

36. Zollner G, Fickert P, Fuchsbichler A, Silbert D, Wagner M, Arbeiter S, et al. Role of nuclear bile acid receptor, FXR, in adaptive ABC transporter regulation by cholic and ursodeoxycholic acid in mouse liver, kidney and intestine. J Hepatol. 2003;39(4):480-8. DOI: $\quad$ 10.1016/s01688278(03)00228-9

37. Yang Q, Onuki R, Nakai C, Sugiyama Y. Ezrin and radixin both regulate the apical membrane localization of ABCC2 (MRP2) in human intestinal epithelial Caco-2 cells. Exp Cell Res. 2007;313(16):3517-25. DOI: 10.1016/j.yexcr.2007.07.033

38. Chang TKH, Bandiera SM, Chen J. Constitutive Androstane Receptor and Pregnane X Receptor Gene Expression in Human Liver: Interindividual Variability and Correlation with CYP2B6 mRNA Levels. Drug Metab Dispos. 2003;31(1):7-10. DOI: 10.1124/dmd.31.1.7

39. Maglich JM, Stoltz CM, Goodwin B, HawkinsBrown D, Moore JT, Kliewer SA. Nuclear Pregnane $\mathrm{X}$ Receptor and Constitutive Androstane Receptor Regulate Overlapping but Distinct Sets of Genes Involved in Xenobiotic Detoxification. Mol Pharmacol. 2002;62(3):638-46. DOI:
40. Wei P, Zhang J, Dowhan DH, Han Y, Moore DD. Specific and overlapping functions of the nuclear hormone receptors CAR and PXR in xenobiotic response. Pharmacogenomics J. 2002;2(2):117-26.

41. Mackinnon AM, Simon FR. Reduced synthesis of hepatic microsomal cytochroma P450 in the bile duct ligated rat. Biochem Biophys Res Commun. 1974;56(2):437-43. DOI: $\quad$ 10.1016/0006$291 \times(74) 90861-4$

42. Leighton JA, Bay MK, Maldonado AL, Johnson RF, Schenker S, Speeg K V. The effect of liver dysfunction on colchicine pharmacokinetics in the rat. Hepatology. 1990;11(2):210-5. DOI: 10.1002/hep.1840110209

43. Buters JT, Zysset T, Reichen J. Metabolism of antipyrine in vivo in two rat models of liver cirrhosis. Its relationship to intrinsic clearance in vitro and microsomal membrane lipid composition. Biochem Pharmacol. 1993;46(6):983-91. DOI: 10.1016/00062952(93)90662-g. 